
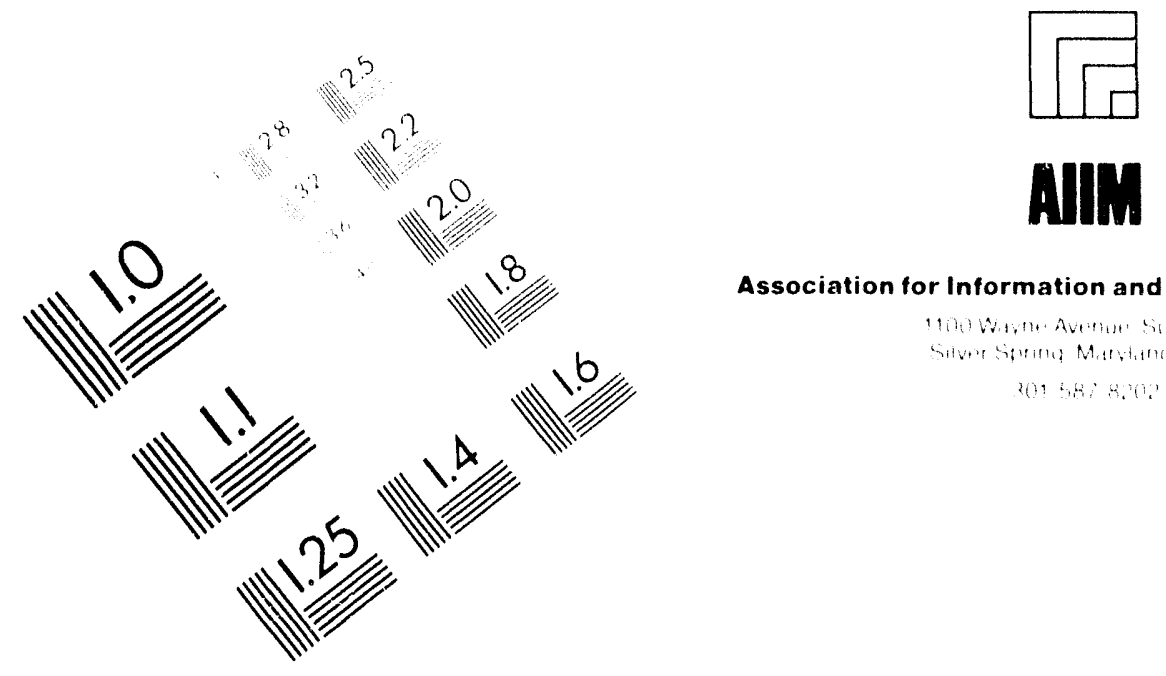

Association for Information and Image Management

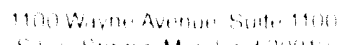

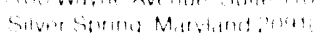

$301,6: 8.0 \%$

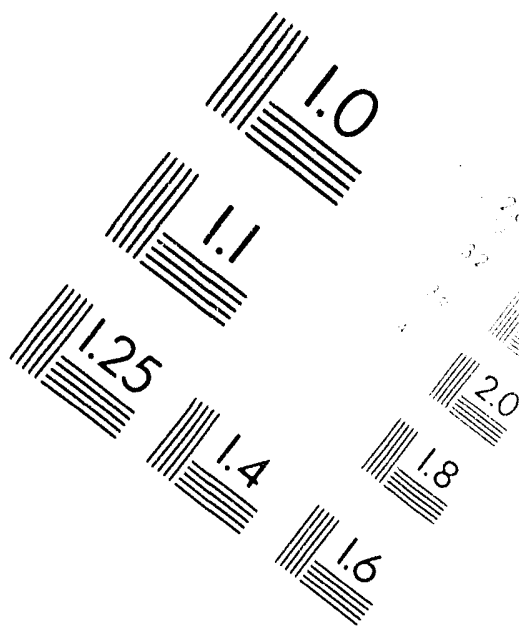

Centimeter

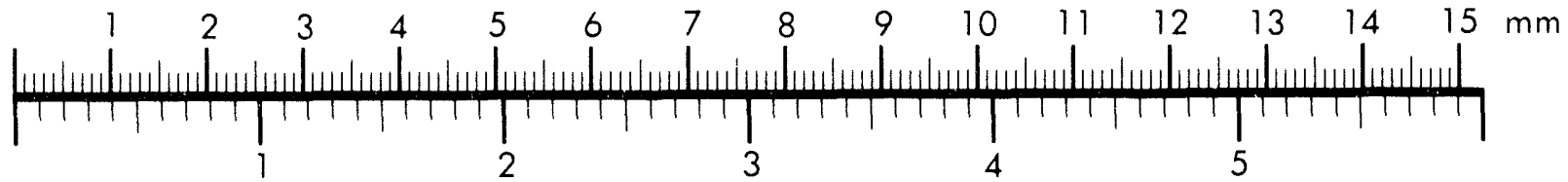

Inches
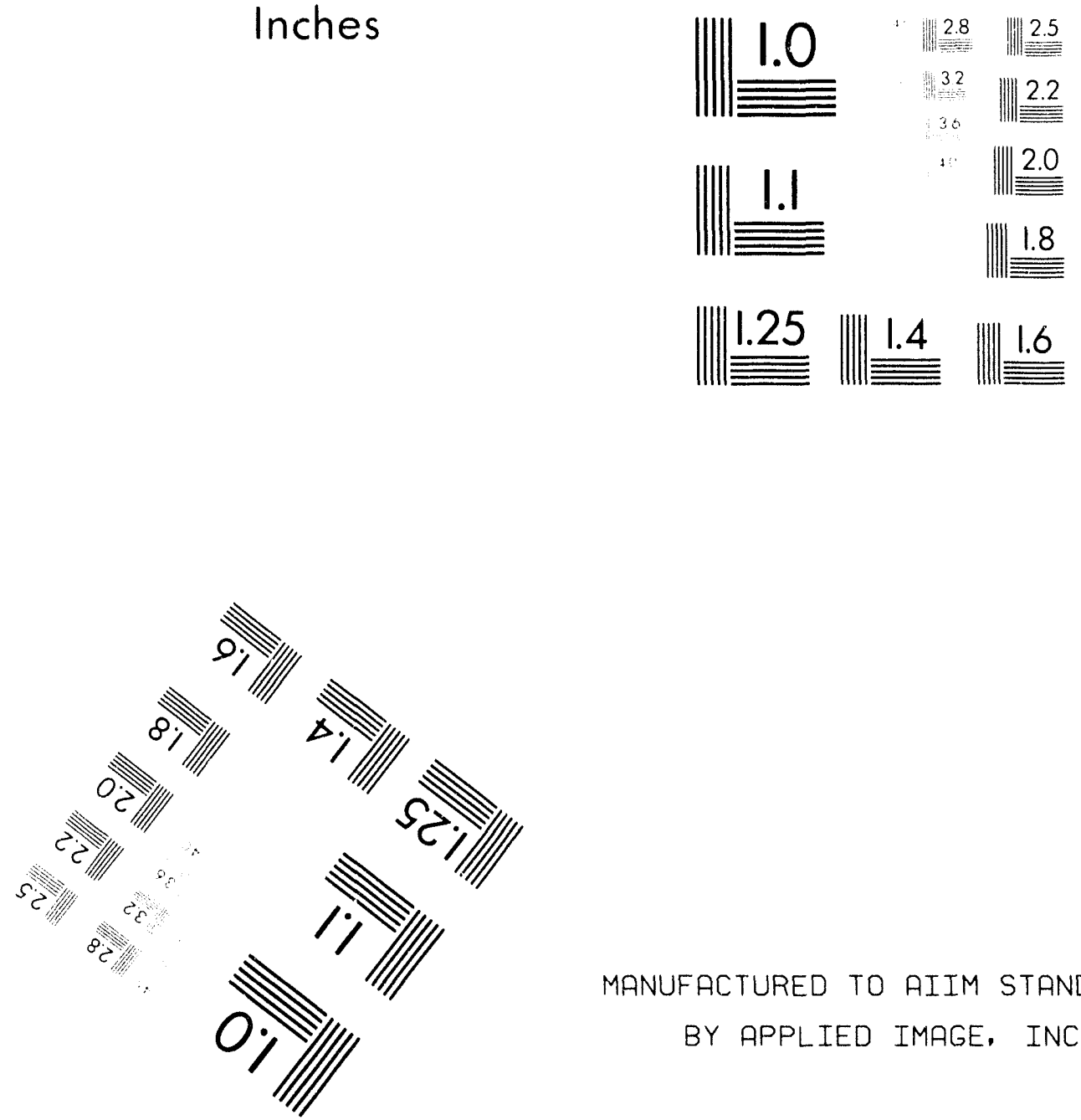

MANUFACTURED TO AIIM STANDARDS

BY APPLIED IMAGE, INC.

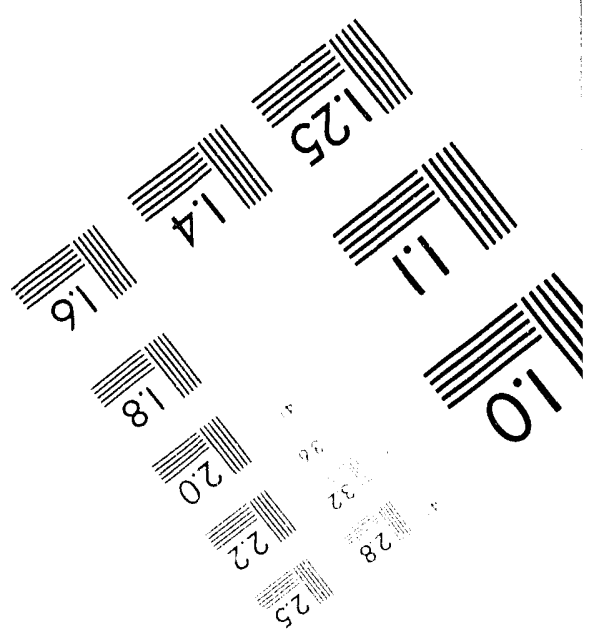



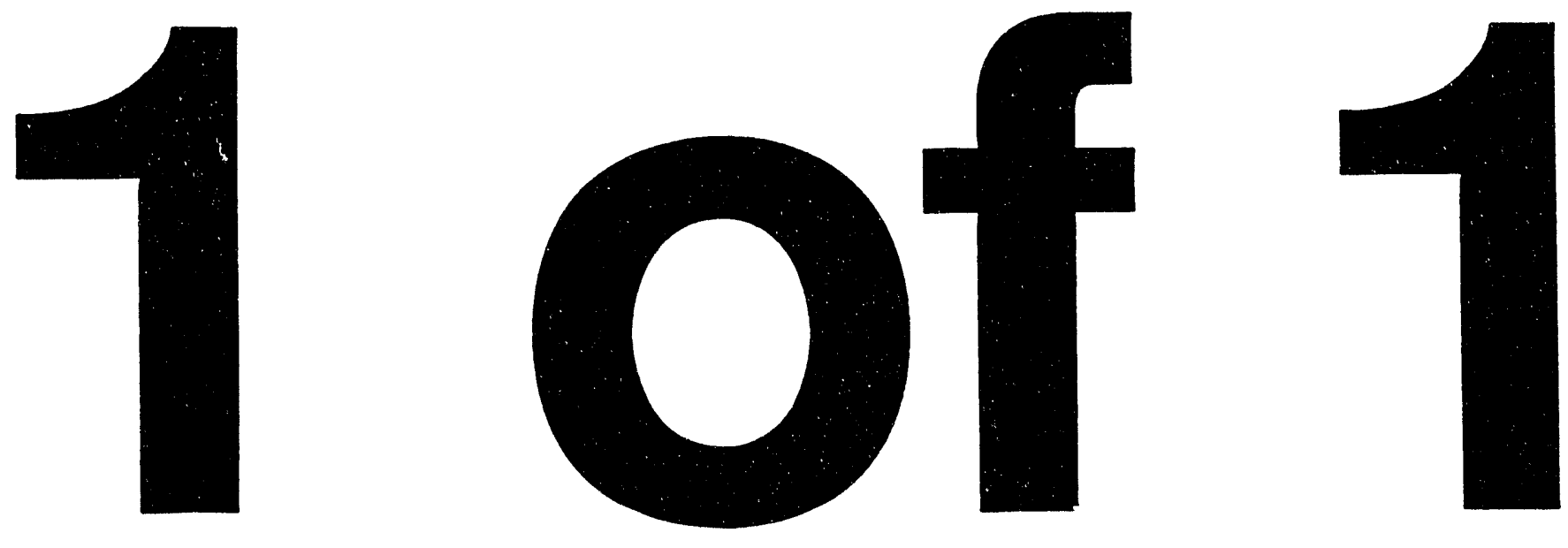


\section{NOVEL MASS SPECTROMETRIC INSTRUMENT FOR GASEOUS AND PARTICULATE CHARACTERIZATION AND MONITORING}

Covering the period from October 1, 1993 through December 31, 1993

Prepared by:

Michael J. Coggiola

SRI Project 4019

Prepared for:

U. S. Department of Energy Morgantown Energy Technology Center

ATTN: Contractor Reports Receipt Coordinator

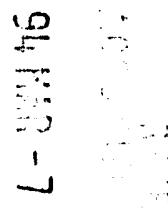

Mail Stop F07

P.O. Box 880

Morgantown, WV 26507-0880

Contract No. DE-AC-21-92MC29116
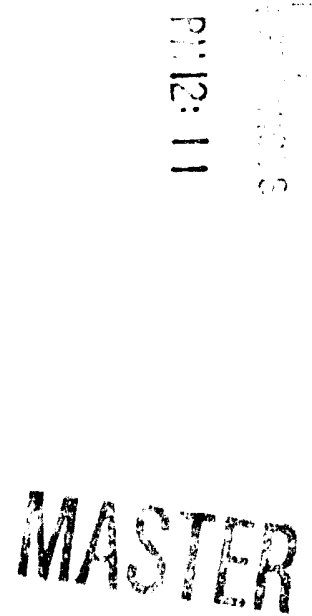


\section{CONTENTS}

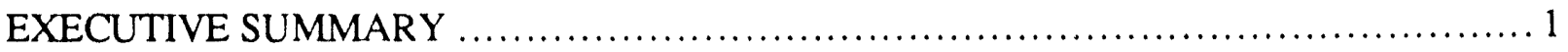

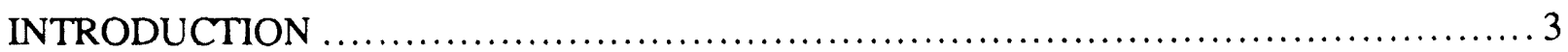

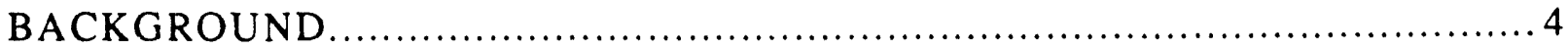

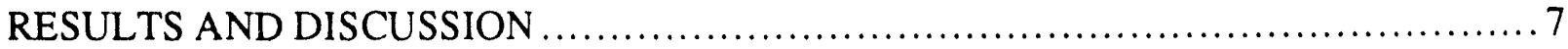

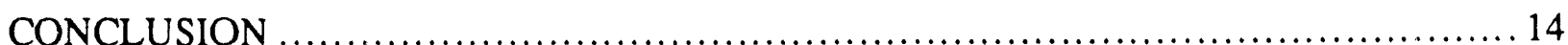

\section{DISCLAIMER}

This report was prepared as an account of work sponsored by an agency of the United States Government. Neither the United States Government nor any agency thereof. nor any of their employees, makes any warranty, express or implied, or assumes any legal liability or responsibility for the accuracy, completeness, or usefulness of any information, apparatus, product, or process disclosed, or represents that its use would not infringe privately owned rights. Reference herein to any specific commercial product, process, or service by trade name, trademark, manufacturer, or otherwise does not necessarily constitute or imply its endorsement, recommendation, or favoring by the United States Government or any agency thereof. The views and opinions of authors expressed herein do not necessarily state or reflect those of the United States Government or any agency thereof. 


\section{EXECUTIVE SUMMARY}

Under contract DE-AC21-92MC29116, SRI International will develop a unique new instrument that will be capable of providing real-time ( $<1$ minute), quantitative, chemical characterization of gaseous and particulate pollutants generated from DOE waste cleanup activities. The instrument will be capable of detecting and identifying volatile organic compounds, polynuclear aromatic hydrocarbons, heavy metals, and transuranic species released during waste cleanup activities. The instrument will be unique in its ability to detect and quantify in real-time these diverse pollutants in both vapor and particulate form.

The instrument to be developed under this program will consist of several major components: (1) an isokinetic sampler capable of operating over a wide range of temperatures (up to $500 \mathrm{~K}$ ) and flow rates; (2) a high pressure to low pressure transition and sampling region that efficiently separates particles from vapor-phase components for separate, parallel analyses; (3) two small mass spectrometers, one optimized for organic analysis using a unique field ionization source and one optimized for particulate characterization using thermal pyrolysis and electron-impact ionization (EI); and (4) a powerful personal computer for control and data acquisition.

The function of the sampler is to obtain a sufficient and representative quantity of air pollutants from a wide range of waste cleanup activities, both vapor and particulate. In addition, the sampler must deliver the vapors and particles to the detection instrument with minimal material loss. The pressure transition region serves multiple functions: (1) it focuses the particles into a "beam" toward the center of the gas flow by momentum separation, (2) it efficiently separates the particulate beam from the vapor stream, allowing independent chemical analyses of particles and vapors, and (3) it provides the first stage of pressure reduction between the ambient atmosphere and the lower pressure (1-2 $\mathrm{Pa}$ ) region of an ion trap mass spectrometer.

Chemical analysis of the volatile organic species and the polynuclear aromatic hydrocarbons is typically accomplished by first enriching their concentration using a dimethylsilicone rubber membrane separator and then analyzing their composition with field ionization mass spectrometry (FIMS). FIMS is a soft ionization method that is ideally suited to the chemical characterization of complex mixtures of organic compounds. Also available will be an alternative direct inlet of vapors bypassing the membrane and use of EI, for comparisons with the membrane inlet and field ionization. Use of EI will permit monitoring of various small inorganic molecules as well, such as $\mathrm{NO}_{\mathbf{x}}$ and $\mathrm{SO}_{\mathbf{x}}$. 
Use of a direct sampling method and differential vacuum pumping allows particulate pollutants to be readily introduced into another ion trap mass spectrometer. Volatilization of particles on a heated surface within the volume of the ion trap followed by the complete and quantitative mass spectrometric analysis of the resulting vapors will yield the detailed information required to monitor waste cleanup activity. Based on conservative estimates of the instrument design and performance parameters, a single $0.1-\mu \mathrm{m}$-diameter particle will provide a signal level sufficient for complete analysis. All these operations are under the control of the data acquisition computer.

The overall goal of this effort is to develop and demonstrate an instrument that can provide real-time, part-per-billion detection sensitivity for important pollutant species generated by DOE waste cleanup activities. Initially, the instrument will be developed for targeted use in conjunction with the K-1435 Toxic Substances Control Act (TSCA) incinerator at the Oak Ridge National Laboratory K-25 site. Ultimately, the instrument will be designed to operate in the field at any cleanup site, located close to the stack or process vent, providing the plant operations personnel with real-time information and alarm capabilities. In addition, this instrument will be very broadly applicable for cleanup or sampling, for example, any time contaminated soil is moved or disturbed. Because of the versatility and analytical power of this instrument, commercialization for a wide variety of applications in monitoring and control will be important.

The instrument relies on both commercially available technology, including a simple laser scattering particle detector, an ion trap mass spectrometer and a membrane permeator, and unique technologies developed by our organization in the area of field ionization mass spectrometry, and high-temperature sampling. These technologies are now at a Maturity Level of II. The instrument is projected to be easily transportable with minimal utility requirements, making it ideal for deployment at a wide variety of DOE waste sites. Moreover, the straightforward design and use of proven technologies will result in an instrument of very high reliability and sensitivity that can be ready for actual field testing and use within two to three years. 


\section{INTRODUCTION}

The goals of the Office of Technology Development as outlined by the director of the Environmental Restoration and Waste Management Program (EM), Leo Duffy, in 1991 appropriations hearings include conducting an aggressive technology development program for waste management, waste minimization, waste treatment, storage and disposal of waste. This will be done through the development of more effective remediation technology to reduce occupational and public exposure. We are developing a method to monitor airborne emissions from the TSCA plant at Oak Ridge which will provide real-time, accurate, and inexpensive data on the emission of hazardous organic and inorganic chemicals in both gaseous and particulate form, and to assist DOE in maintaining its ambitious schedules and overcoming significant scientific limitations of its current monitoring technologies.

In May 1988 under the Comprehensive Environmental Response, Compensation, and Liability Act (CERCLA), Oak Ridge National Laboratory (ORNL) established a timetable remedial investigation/feasibility study, and a Federal Facility Agreement is being negotiated with the Environmental Protection Agency and the Tennessee Department of Health and Environment. As a result, work has begun on inactive waste sites at ORNL to excavate and isolate wastes in compliance with current standards. In addition, ORNL must comply with the Resource Conservation and Recovery Act (RCRA), which regulates generation, transportation, treatment, storage, and disposal of hazardous wastes and corrective action of releases to the environment of hazardous wastes from active facilities.

Environmental restoration activities at DOE-ORO sites and facilities, such as K-25 and Y12, are conducted to meet location, contaminant, and action-specific requirements imposed by statues and regulations and to implement guidance and agreements. These activities typically follow a phased approach with public involvement throughout the process.

A key responsibility of the Oak Ridge Operations Office is for the environmental remediation and restoration activities at the Oak Ride e, Y-12 and K-25 facilities. Support of both the Department of Energy's and the State of Tennessee's commitment to environmental issues is a vital concern of the Oak Ridge site's work force and management structure. Through advances in technology, the environmental remediation and restoration efforts may be accomplished at less cost, and with a decreased impact on the surrounding communities. 


\section{BACKGROUND}

The Oak Ridge K-25 site is located 13 miles west of Oak Ridge. Until the summer of 1985 , when the gaseous diffusion process was shut down, the mission of the K-25 site was ${ }^{235} \mathrm{U}$ enrichment of uranium hexafluoride $\left(\mathrm{UF}_{6}\right)$ for eventual use as a fuel in nuclear reactors. Typical facilities included the feed system and separate systems for collecting the product and the waste (tails) stream. The purging of contaminants from the product stream required the use of large amounts of alumina and sodium fluoride. A number of compounds were used for the clarification of coolant water, and hexavalent chromium, zinc, and phosphate were used to inhibit corrosion of heat transfer equipment. Support facilities produced solutions that required concentration and recovery with some residual that was discarded and buried. Laboratory sample residues and obsolete chemical reagents, spent chemicals, and contaminated equipment were candidates for discard. Sludges from chemical wastes contain hazardous materials, including chromium, copper, lead, mercury, naphthalene, and zinc. Wastes buried at the K-25 site include low-level radioactive solid waste, mixed chemical waste, and radioactive and nonradioactive classified materials. Uranium was released into the air, surface water, and on-site land disposal.

Waste management activities at the K-25 site are increasing. Low-level radioactive waste from other DOE-Oak Ridge Operations (ORO) sites are now being placed in interim storage facilities in the K-25 site building vaults until final disposition strategy is identified. Also, polychlorinated biphenyl (PCB) wastes began arriving from other DOE-ORO sites in 1987 for future incineration in the new K-1435 Toxic Substances Control Act incinerator.

Making an analogy, it is well established that heavy metals are present in the stack emissions of coal-fired power plants. Considerable research in thic area has identified every naturally occurring element in coal fly ash, with concentrations ranging from percents to parts-permillion and below. In the case of coal combustion, these heavy metals are present in the feed stock, whereas in the process stream of a waste cleanup facility, many heavy metals will be present at high concentrations as part of the original waste material. Although a number of the naturally occurring elements are of minor concern, many of the heavy metals, such as mercury, lead, cadmium, arsenic, chromium, and uranium, pose significant health risks to humans. Additionally, the transuranic elements such as plutonium, are of particular concern due to their extreme toxicity as respirable particles. Many other elements, both radioactive and nonradioactive, also pose health and safety risks. Included in this category are particles containing beryllium, iodine, and cesium. 
By analogy with the known distribution of heavy metals within airborne particles generated by coal-fired power plants, it is reasonable to conclude that significant levels of heavy metals and hazardous inorganic contamination can be unknowingly discharged from process vent stacks in the particulate form. To maintain a high degree of safety and control over cleanup activities at waste sites containing these materials, a monitoring instrument is required that can provide real-time, quantitative measurements of levels of important elements at any point within the process. Particular attention must be given to effluent discharge to the atmosphere via vents and stacks to prevent any release of hazardous by-products of the cleanup activities.

In addition to the heavy metal and inorganic emissions, a very wide range of VOCs will be produced and emitted from any waste cleanup plants, including PAHs, heterocyclic nitrogen and sulfur species, and polychlorinated biphenyls (PCBs). Many of these VOCs are known or suspected carcinogens whose levels must also be controlled. Unlike the metals and inorganic species, many of the organic compounds found in the gaseous effluent of waste cleanup facilities will include materials not initially present in the waste stream. For example, many PAHs are formed during the incomplete combustion of simple organic wastes. As with metals and inorganics, the organic pollutants can be released in both the vapor and particulate forms. Thus, a versatile real-time instrument for determining VOC levels is required to allow plant operators to monitor and regulate stack emissions of these hazardous species.

Any real-time waste cleanup process monitor should be capable of simultaneously measuring numerous important chemical species, both organic and inorganic, present as vapors and particles. Although very sophisticated monitoring technologies are currently under development that make use of optical, clectrochemical, and microsensor methods, none yet offers quantitative chemical characterization of both vapor phase and particulate air pollutants. Moreover, most of these sophisticated sensors are capable of detecting only one or two specific chemical species, thereby requiring that many separate sensors be integrated to perform the necessary monitoring and control functions. Such multisensor systems will often be technologically more complex and less reliable than a single, multifunctional instrument, as well as more costly to develop, manufacture, operate, and maintain.

The most universal analytical technique available for monitoring a broad range of chemical species is mass spectrometry. If mass spectrometry is to be used, however, the sampled materials must be vaporized and ionized before analysis. The ionization method must be carefully chosen to prevent preferential, or nonstatistical, ionization while providing adequate and stable signal levels. Even before the effluent can be ionized, it must be sampled and transported from the stack or process stream to the ionizer. In the case of a waste cleanup plant such as the K-1435 TSCA incinerator at the DOE-Oak Ridge Operations site, the sampled effluent will consist of vapors and 
particles. Thus, the development of an appropriate sampler will be a critical aspect of this effort. Most of the heavy metals, for example, will not appear in vapor form, but will be incorporated into particles of varying sizes. Not only must these particles be efficiently sampled, they must also be separated from the vapor component and then completely vaporized to provide the requisite composition information. At the same time, the sampled vapors, including the organic species of interest, must be isolated and efficiently detected. No single instrumental technique (FTIR, ICPAES, ICP-MS, GC, GC-MS, LIF) is capable of simultaneously detecting both organic and inorganic species in vapor and particulate forms. However, a single instrument consisting of two closely integrated detectors that share a common sampler can provide this critical analytical capability. 


\section{RESULTS AND DISCUSSION}

To goals of this research program are to develop, demonstrate, and field test a real-time monitoring instrument capable of providing quantitative chemical information on the vapor and particulate emissions produced during the incineration of toxic waste. The Phase I effort is divided into five main tasks and subtasks as follows:

Task 1: NEPA Documentation

Task 2: Instrument Development

Task 2.1: Sampler Development

Task 2.2: Vapor Instrument Development

Task 2.3: Particulate Instrument Development

Task 3: Instrument Testing

Task 3.1: Single Metal Species Testing

Task 3.2: Multiple Metal Species Testing

Task 4: System Design

Task 5: Project Management

A key clement of the Task 2 effort is the design of the particle sampler and its interface with the ion trap. This design requires a knowledge of the spatial distribution of the particles as they traverse the sampler and enter the trap. The basic concept of the experiment is to direct the particle beam at a target coated with an adhesive layer that would trap the particles for subsequent analysis. An experiment was performed using a beam of latex particles in order to investigate any bias in the sampling associated with particle size. By using particles dyed red $(0.5 \mu \mathrm{m})$, green $(1 \mu \mathrm{m})$ and blue $(3.7 \mu \mathrm{m})$, we can easily distinguish their spatial distribution using a fluorescence microscope. A 1:1:1 mixture was prepared, and a set of experimental runs was completed. Using this mixture, runs were made with nozzle-skimmer distances of 1,5 , and $7 \mathrm{~mm}$, each for 10 and 15 minute duration. A detailed microscopic analysis of the resulting distributions has been performed, with the results discussed below.

Figure 1 shows the results of using a monodisperse beam of $0.482 \mu \mathrm{m}$ blue particles. The photograph shows a well define circular pattern with a diameter of approximately $0.80 \mathrm{~mm}$. 
Figures 2-4 show the corresponding circular patterns measured using a 1:1:1 mixture of $2.00 \mu \mathrm{m}$ (blue), $1.01 \mu \mathrm{m}$ (green), and $0.508 \mu \mathrm{m}$ (red) latex spheres. These three photographs were made from the same deposited spot using three optical filters on the microscope. The measured radial distribution of each size particle is plotted in Figure 5 for three separate runs. These data clearly show that the largest particles are more strongly focused near the center of the beam. While this is not surprising, we also observe that the total number of particles collected of each size is not the same. For example, the total number of the largest particles collected is approximately 150, while the corresponding total for the smallest particles is between 500 and 600 . This disparity could either reflect a sampling bias or a bias in the particle beam generation. Ultimately, this two uncertainty will be resolved by collecting particles at the exit of the particle beam generator nozzle. If that sample shows no bias, then the results in Figure 5 must have arisen from a bias in the sampling of the particles by the differentially pumped skimmer system. 


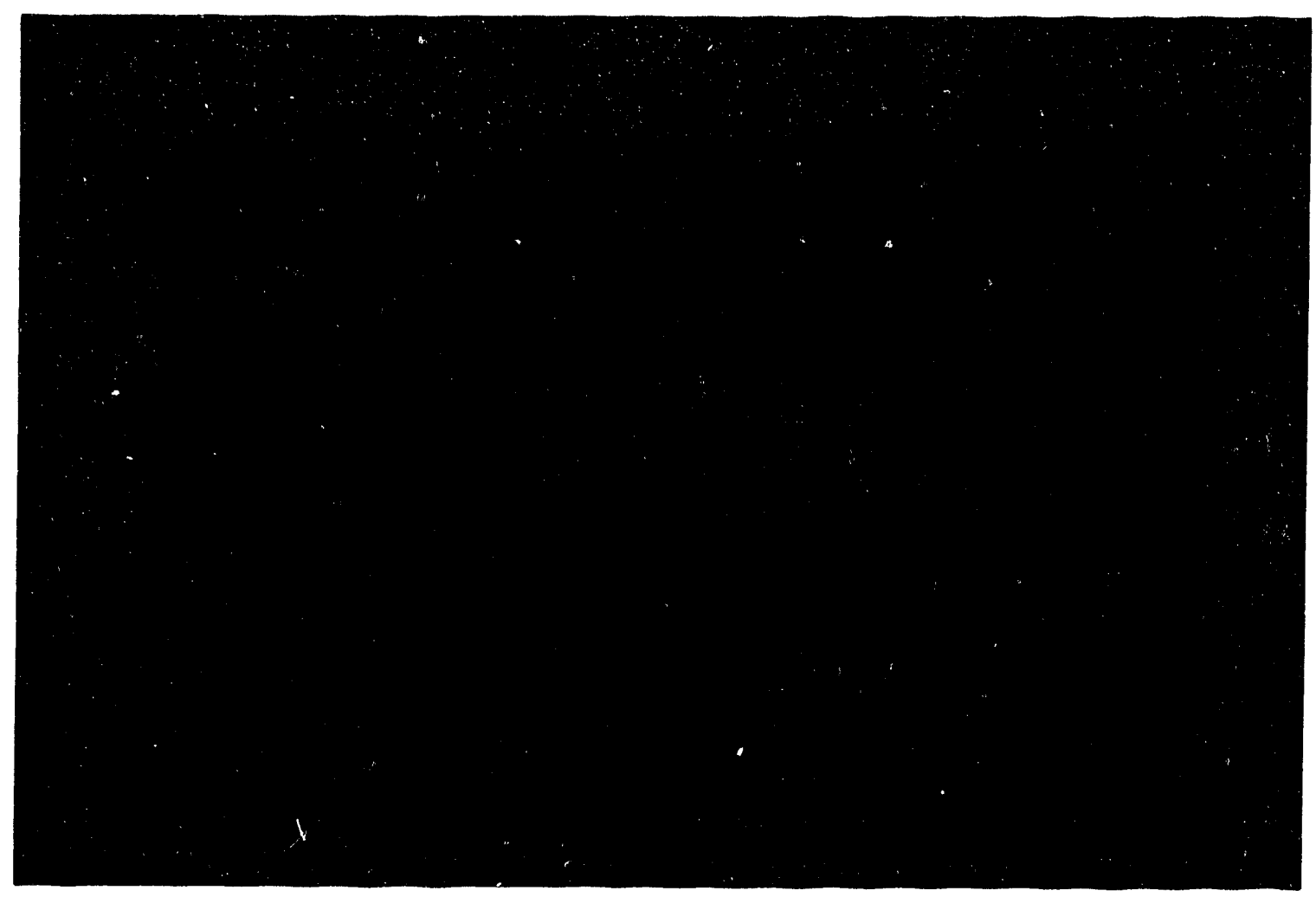

Figure 1. Photograph of $0.482 \mu \mathrm{m}$ latex particles collected on a stainless steel foil coated with silicone grease.

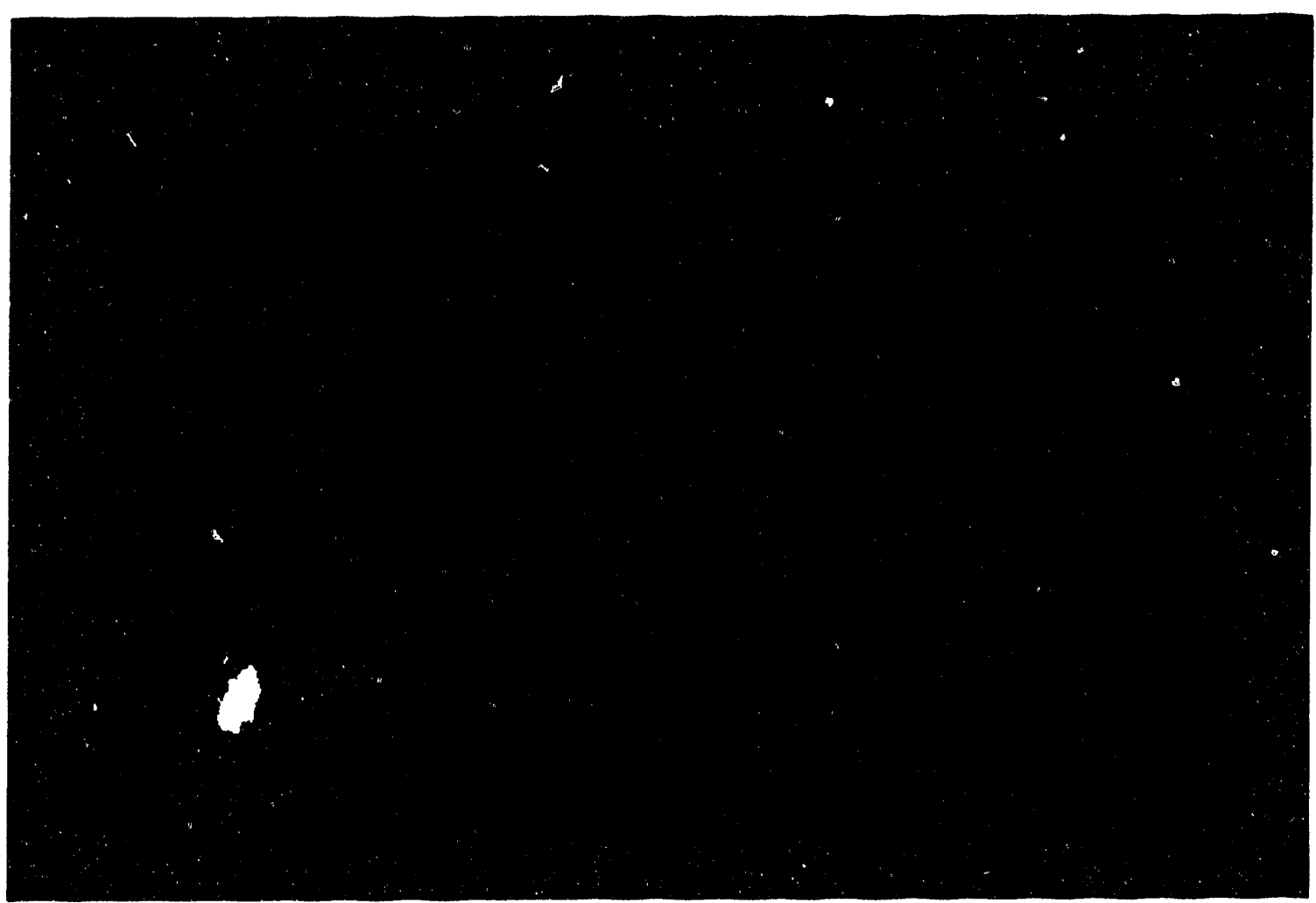

Figure 2. Photograph of $2.0 \mu \mathrm{m}$ latex particles collected on a stainless steel foil coated with silicone grease. 


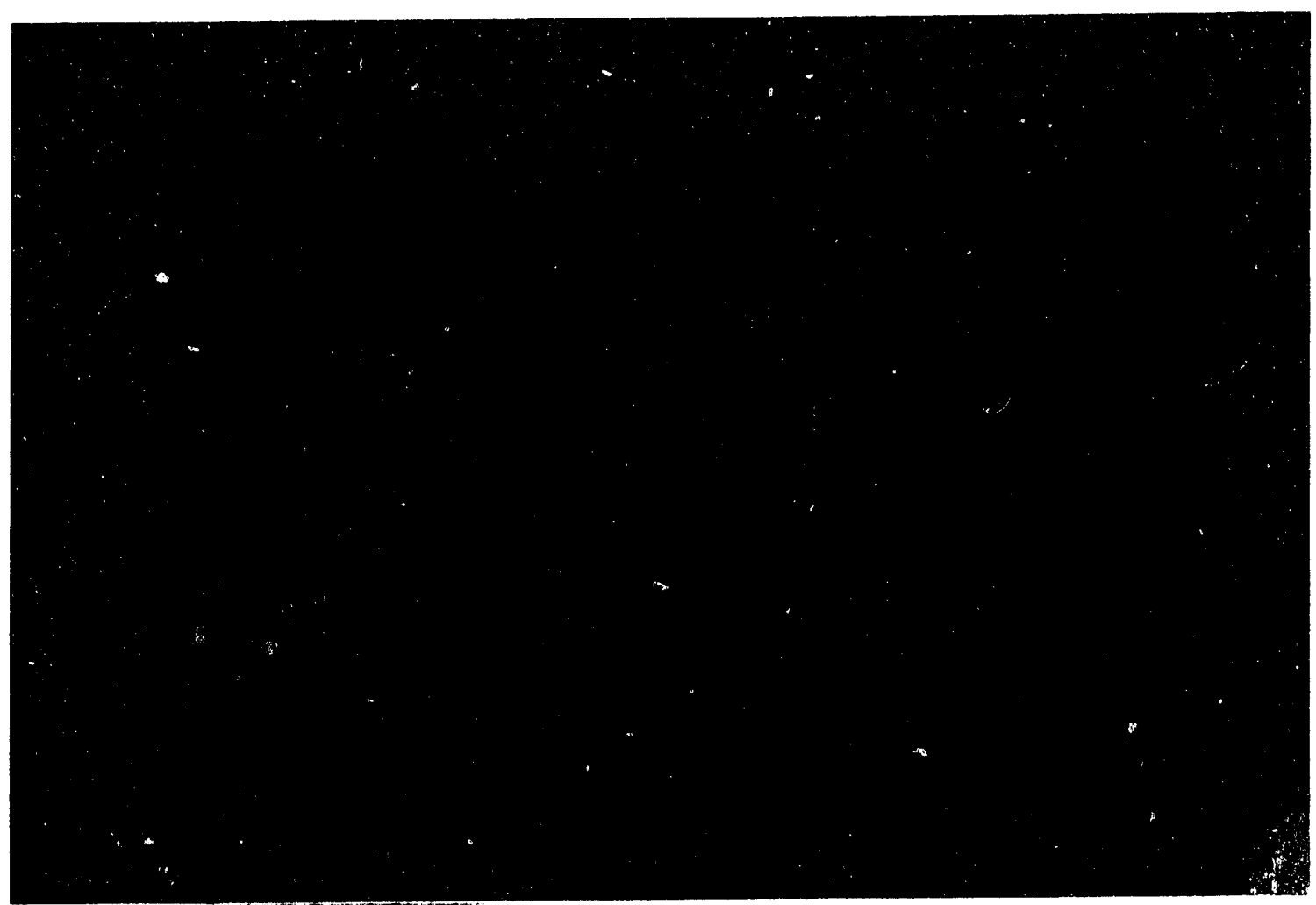

Figure 3. Photograph of $1.01 \mu \mathrm{m}$ latex particles collected on a stainless steel foil coated with silicone grease.

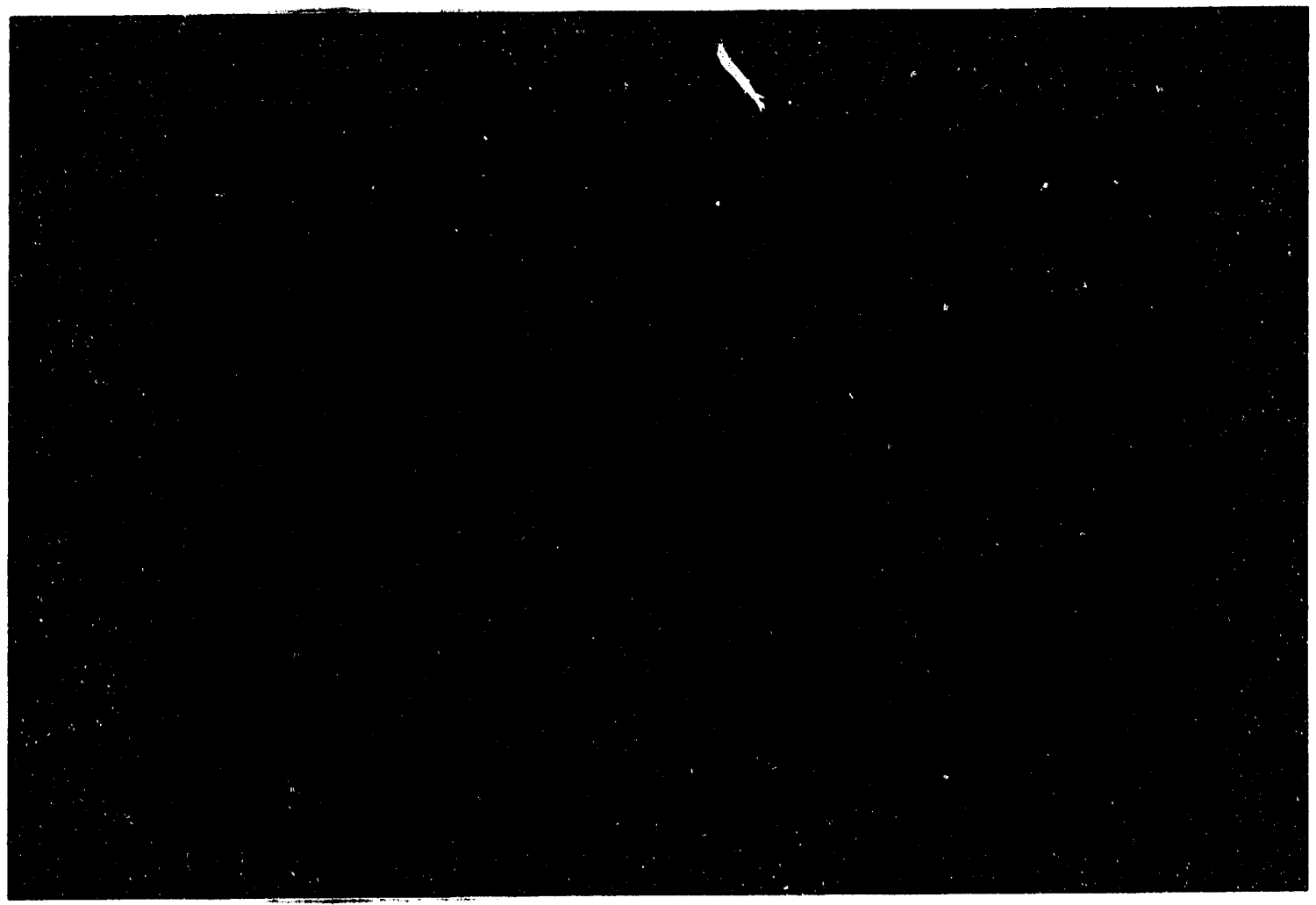

Figure 4 Photograph of $0.508 \mu \mathrm{m}$ latex particles collected on a stainless steel foil coated with silicone grease. 


\section{Radial Distribution}

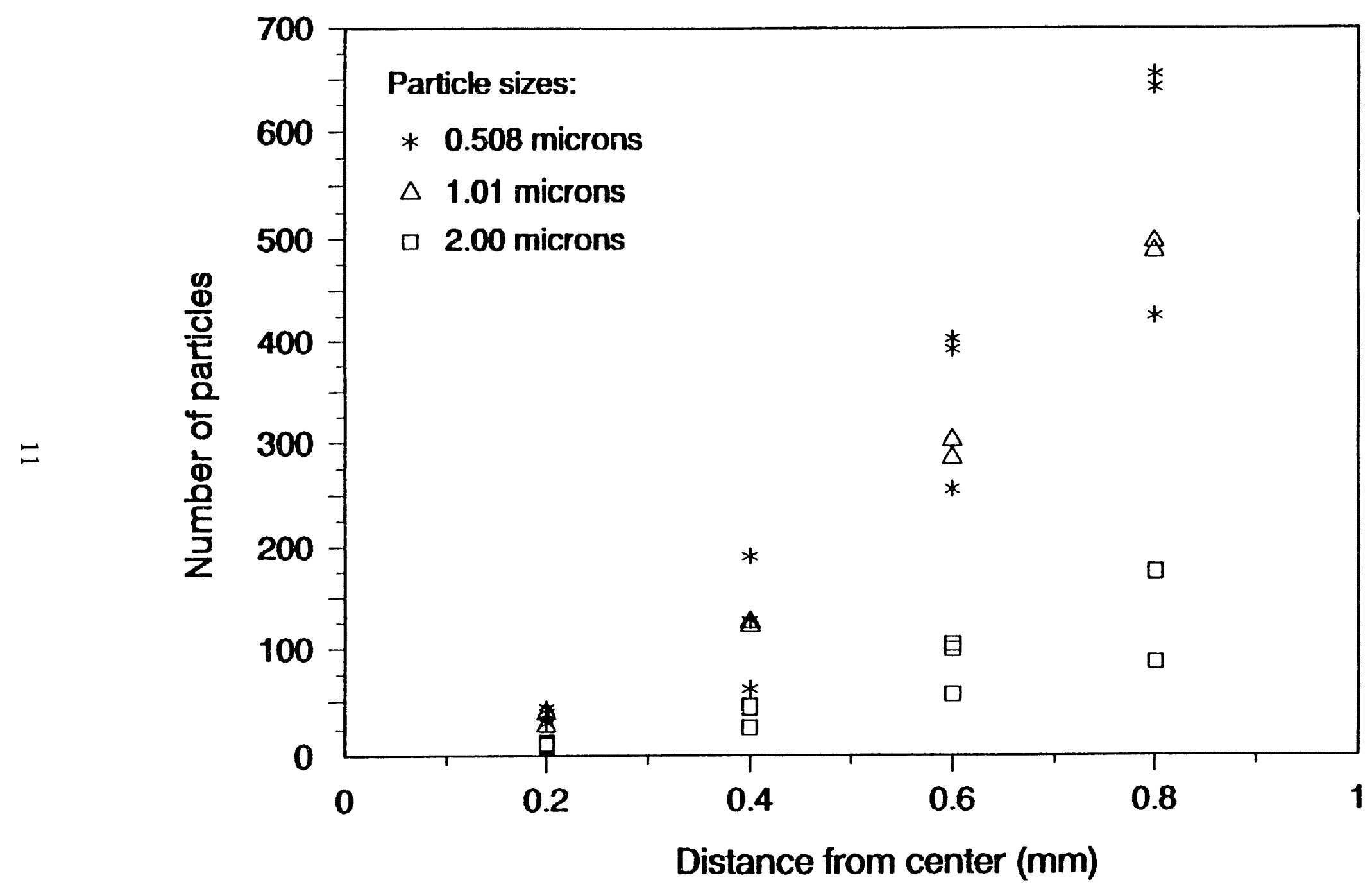

Figure 5. Measured radial distribution of latex spheres as a function of diameter. The entire collection area has a diameter of $0.8 \mathrm{~mm}$. Multiple runs are plotted for each size particle. 
Using an alignment jig previously developed, we successfully aligned the final particle beam forming aperture with the other skimmers. We verified the alignment by collecting a particle sample on a coated slide positioned approximately $3.5 \mathrm{~cm}$ downstream from the final aperture. Using the same $1: 1: 1$ mixture of $0.5,1.0$, and $2.0 \mu \mathrm{m}$ diameter latex particles and the microscope equipped with uv-induced fluorescence detection, we have measured the final beam size to be 0.78 $\mathrm{mm}$. This beam size is smaller than the $2 \mathrm{~mm}$ diameter entrance channel in the ion trap, indicating that we can increase the beam defining aperture sizes to increase sensitivity as necessary.

Also during this reporting period, the entire trap assembly was mounted within the vacuum chamber and aligned with the particle beam axis. The mounting process involved the complete assembly and testing of a positioning system that allows the trap to be aligned with the particle beam axis. This positioning and mounting system includes both the mechanical motion as well as the electrical connections between the vacuum flange and the ion trap itself. All of the internal ion trap wiring was done using vacuum compatible materials

All of the necessary electronics was also be interfaced with the ion trap and pyrolysis filament so that mass spectra of volatilized test particles could be measured. Once the ion trap electronics were installed, it was be necessary to retune the rf to account for changes in the cable capacitance. After retuning, the ion trap operated normally, although the background mass spectrum showed significant outgassing by some of the polymer materials used to fabricate the ion trap positioning components. Several unsuccessful attempts were made to observe the mass spectrum of pyrolyzed latex particles introduced into the trap by the beam. Additional attempts to align the ion trap entrance channel with the particle beam in real time were also not successful. Because we had previously verified the alignment of the beam generation nozzle with both of the skimmers, it was clear that the ion trap was not aligned with the beam axis. To facilitate alignment of the beam axis with the ion trap, we then used an optical alignment procedure. The particle beam delivery system was temporarily removed and a small $\mathrm{HeNe}$ laser was used to define the beam line. The pyrolysis filament was removed from the trap to allow the light to pass completely through. We quickly discovered that the ion trap was rotated considerably from the correct straight line path. In other words, when the laser beam entered the ion trap channel, it did not exit through the pyrolysis filament opening. This misalignment would ensure that no particles would reach the filament.

After discovering that the ion trap was rotated considerably from the correct straight line path, the trap was properly positioned. With the trap and particle beam aligned, we initiated an experiment to detect the molecular beam formed by the expansion of the butanol/argon through the sampling nozzle. We would expect that this molecular beam would provide a measurable mass spectrometric signal that was sharply peaked, and spatially well-defined, corresponding to the 
optimum alignment of the ion trap entrance channel with the beam. Although we did note a slight increase in the signal that was attributable to the argon carrier gas, its magnitude was considerably smaller than expected, as was its broad spatial extent. Upon closer examination of the relative pressures in the first differential region and the ion trap region, it was apparent that conditions were not conducive to the formation of a true supersonic molecular beam. The primary difficulty appeared to be the excessive pressure (1-5 mTorr) in the region of the first sampling skimmer. Such a high pressure can easily lead to multiple gas collisions in the vicinity of the skimmer throat, with a significant loss of beam intensity through scattering. In order to remedy this situation, we modified the apparatus so that the first differential pumping region could be maintained at a lower pressure. This was accomplished by replacing the mechanical pumping system with a small, 210 $1 / \mathrm{sec}$ diffusion pump. The change in pumping required some minor modifications to the vacuum housing, including the addition of an ionization gauge that will allow a better measure of the pressure in this region. Preliminary tests of the system following these changes indicate that the molecular beam formation process is considerably enhanced. Under the new conditions, we are able to mechanically scan the position of the ion trap with respect to the anticipated beam axis and observe a distinct and sharp maximum in the argon signal measured by the mass spectrometer. We also know that the pressure in the first differential pumping region is sufficiently low to avoid the scattering losses previously encountered. 


\section{CONCLUSION}

With the new pumping and alignment arrangement, we will begin testing the system with the latex particle beam. Initially, we will operate the beam for a short period of time with the pyrolysis filament off to accumulate particle on its surface. The filament will then be flash heated while observing the ion trap signal. The reason for using this mode of operation rather than looking for single particle events is our lack of ability to externally trigger the ion trap scan. Installation and testing of the laser light scattering system has been deferred until a reliable sample introduction system was operational. The development of a reliable and reproducible trigger signal is critical to the particulate analysis function. Once this trigger signal is available, appropriate modifications to the ion trap hardware/software will be required to initiate a mass analysis scan that is synchronized with the particle arrival and vaporization. Prior to having a particle trigger signal, we will allow the ion trap to operate in a free-run mode that is not synchronized with the particle arrival. The resulting mass spectra will represent an average of many particles rather than single particle spectra, however, the basic operation of the system will be verified. Although we have been in contact with a number of ion trap users, developers, and manufacturers, no one has yet been able to assist us in dealing with this problem. We have recently talked with the $R \& D$ group at Finnigan MAT, and plan to continue pursuing the solution to this difficulty.

At the completion of the first fifteen months of this research effort, overall progress of the effort is behind on schedule by several months, due primarily to numerous difficulties associated with the particle sampling, transport, and introduction into the ion trap. Despite these difficulties, we have made a significant amount of technical progress on developing a real-time monitoring instrument for use by DOE. In our discussions with other DOE and national laboratory researchers, it is clear that the need for this instrument remains critical since new monitoring technologies have the highest priority. We are also not aware of any related efforts by others to develop an instrument with comparable capabilities. DOE headquarters continues to emphasize the need for high payoff/high risk technology development in the area of environmental waste management. We still view our project as having a high payoff with only moderate risk.

Recently, it has become clear that some milestones scheduled for the first phase will require additional time for completion. Some delays in component acquisition and construction, unforeseen technical difficulties in the efficient sampling and transport of particulates, a 17-month period or performance rather than the anticipated 18-month period, and perhaps an optimistic initial schedule, are the reasons for requiring additional time. Within the last month, however, we have 
seen the first clear evidence of particulate detection, leading to renewed optimism that we can adequately demonstrate the viability of our concept, and move into the next phase of development. 

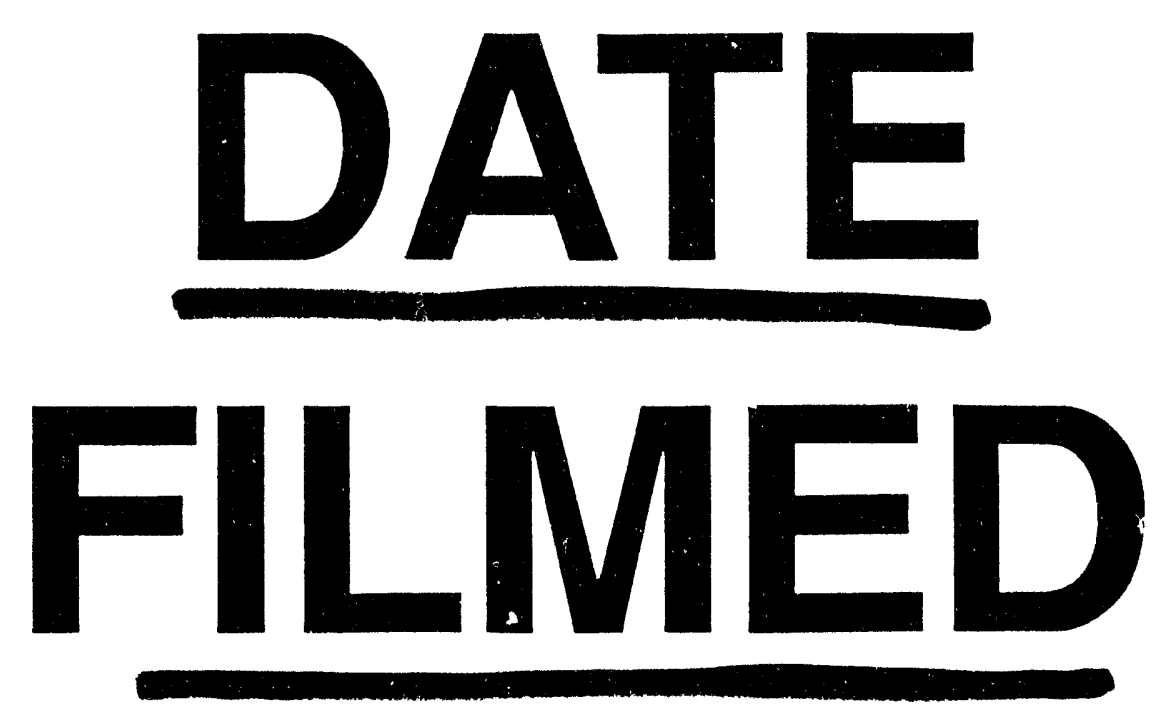

$8 / 9 / 94$
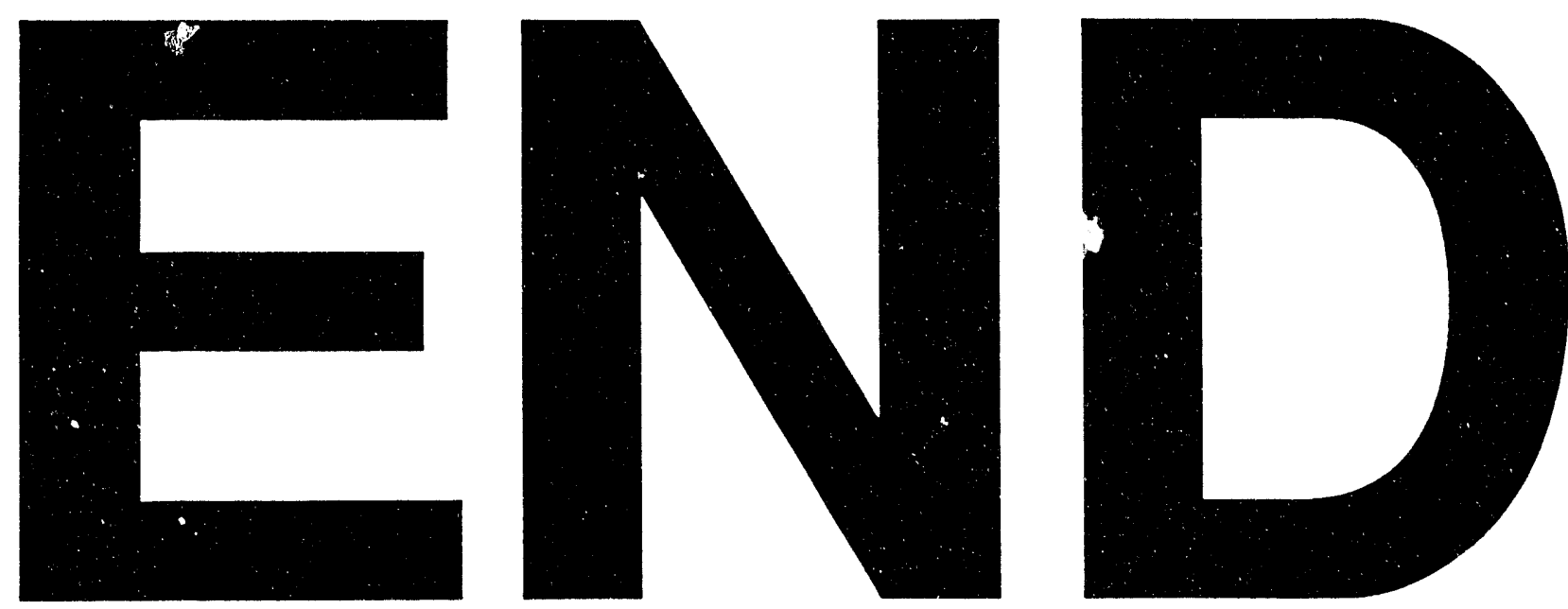
